\title{
Capability development of local communities for project sustainability in afforestation/reforestation clean development mechanism
}

\author{
Makino Yamada Yamanoshita • Masahiro Amano
}

Received: 28 June 2011 / Accepted: 25 October 2011 /

Published online: 12 November 2011

(C) The Author(s) 2011. This article is published with open access at Springerlink.com

\begin{abstract}
It has been recognized that the involvement of local community is essential to ensure the sustainability of A/R CDM (afforestation/reforestation clean development mechanism) project. This study verifies if the risks of non-permanence and leakage are addressed in a registered small scale A/R CDM project in Vietnam. Workshops, interviews, and a questionnaire survey of local villagers revealed that the project has caused a shortage of land for conventional activities such as grazing, fuel wood collection and shifting cultivation, and consequently posed the risks of project non-permanence and leakage. It is suggested that participation of all stakeholders in the community to the A/R CDM project beyond existing land tenure and adequate carbon benefit sharing according to the level of contribution to the project are required to reduce the risk of non permanence. To ensure the participation, the community should have capability such as consensus building and collective action. Leakage would be minimized if the community has alternative measures to the conventional activities before starting the project. We argue that it is necessary to first develop a community's capabilities in the readiness phase of any $\mathrm{A} / \mathrm{R} \mathrm{CDM}$ project in order to reduce the risks for the project sustainability, and that new sources of funding are needed for this purpose.
\end{abstract}

Keywords A/R CDM - Capacity building - Community forestry · Forest carbon project . Payment for environmental services (PES) $\cdot$ Sustainable forest management $\cdot$ REDD +

\section{Introduction}

Forestry mitigation options hold significant economic potential through afforestation/ reforestation $(\mathrm{A} / \mathrm{R})$ activities, and reducing deforestation and forest degradation (REDD) activities, at a cost of up to U.S. $\$ 100$ per ton of carbon dioxide equivalent $\left(\mathrm{tCO}_{2}\right.$-eq), and potentially contributing to a reduction of up to 2.7 gigatons (Gt) of $\mathrm{CO}_{2}$-eq emissions per year by 2030, representing about $7 \%$ of the 1990 global anthropogenic greenhouse gas

M. Y. Yamanoshita $(\bowtie) \cdot M$. Amano

Environmental Planning Laboratory, School of Human Sciences, Waseda University, Mikajima,

Tokorozawa, Saitama 359-1192, Japan

e-mail: macchino@akane.waseda.jp 
(GHG) emissions (IPCC 2007). At the same time, forests already provide economic, environmental, and socio-cultural benefits and services to millions of forest-dependent people, as well as habitats for fauna and flora. A/R and REDD activities are important options not only in any global climate mitigation strategy but also in any sustainable development strategy, especially in developing countries.

The United Nations Framework Convention on Climate Change (UNFCCC) adopted A/R activities as a part of the Clean Development Mechanism (CDM) under the Kyoto Protocol (KP) and subsequently REDD+-Reducing Emissions from Deforestation and Forest Degradation "plus" conservation, i.e., sustainable management of forests and enhancement of forest carbon sink stocks - as a new post-KP mechanism (UN 1998; UNFCCC 2010). The carbon mitigation potential resulting from $\mathrm{A} / \mathrm{R} \mathrm{CDM}$ and REDD+activities obviously differs by country. Figure 1 plots the proportion of forest area in 2010 and average annual change in forest area between 2005 and 2010 in Asian developing countries (FAO 2010). REDD+ activities can be applied in countries with a high proportion of forestland and a high deforestation rate - such as Indonesia, Cambodia, Lao, and Myanmar. On the other hand, China, Vietnam, the Philippines, and India have already deforested large parts of their forests and shifted to increasing their forest area through $\mathrm{A} / \mathrm{R}$ activities. These countries have high mitigation potential if they take advantage of the A/R CDM scheme. In order to harness the mitigation potential of forests, each country should select the most suitable forestry options depending on the state of their forests and forest policy, and then move to action.

There are the particular risks of non-permanence (the risk that emission removals by sinks may be reversed if forests are cut or destroyed by natural disaster) and leakage (increase in GHG emissions by sources outside the project boundary attributable to the $\mathrm{A} / \mathrm{R}$ $\mathrm{CDM}$ project activity) associated with $\mathrm{A} / \mathrm{R}$ projects. Because these risks were regarded as factors that could seriously affect the reliability of carbon credits issued from $\mathrm{A} / \mathrm{R}$ projects, expiring temporary credits and rules for sophisticated monitoring were adopted to facilitate carbon accounting in market mechanisms. Expiring credit made it possible to get the implementation periods of reduction measures to coincide with the end of the capital's

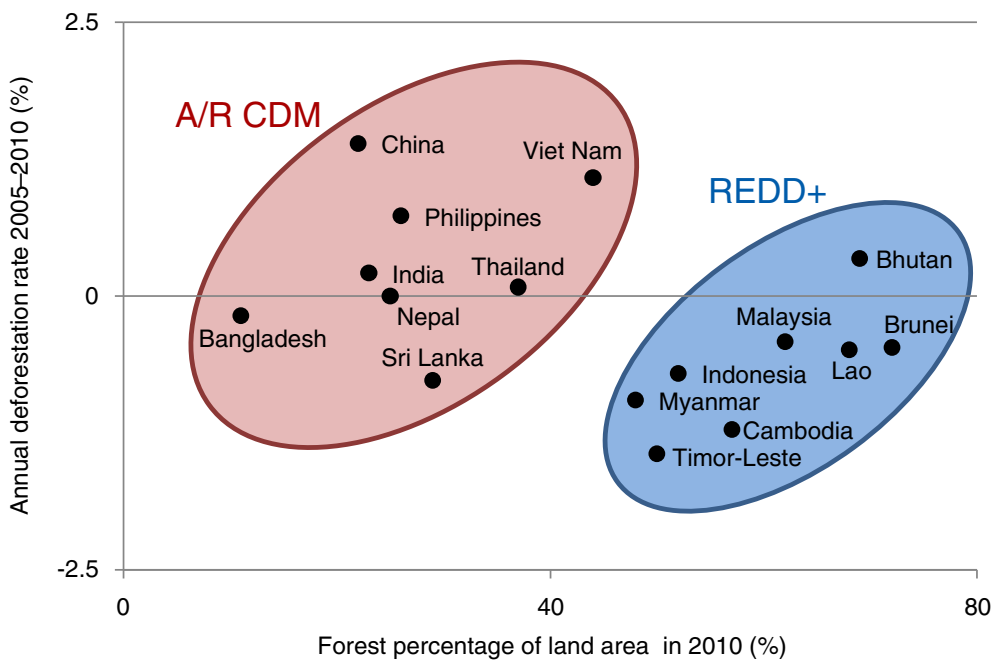

Fig. 1 Suitable forest mitigation options, by country, in tropical and sub-tropical Asia Note: REDD+is applicable in countries with a high proportion of forest and high deforestation rate. A/R CDM projects are applicable in countries that have been deforested and are increasing their forest area 
economic life for the buyers and allowed for the implementation of small short term project for the sellers (Marechal and Hecq 2006). Nevertheless, the A/R CDM has not been widely applied to forestry projects in developing countries during the first commitment period of the KP. In fact, only $22 \mathrm{~A} / \mathrm{R} \mathrm{CDM}$ projects were registered, while there were more than 3,000 registered as CDM projects in energy sectors, as of May 2011 (UNFCCC 2011b).

Financial, institutional, and administrative obstacles were found in various $\mathrm{A} / \mathrm{R} \mathrm{CDM}$ project developments (Dargusch et al. 2010). Especially, it has been found that the low price of expiring temporary credits and the complex rules are major constraints (Rocha 2008; Streck et al. 2009b; Lasco et al. 2010; Tal and Gordon 2010). The expiring temporary credit was not attractive to carbon investors, and the price tended to be far lower than for other carbon emission reduction projects (Tal and Gordon 2010). Consequently, income from Carbon credit is not sufficient to recover the cost of tree planting (Lasco et al. 2010). The rules are complex, unfeasible, and unfairly beyond the capacity of poor communities (Minang et al. 2007).

Demonstrated project quality may have a positive effect on the price of CERs and an important criterion of good quality will be how the risk of reversing $\mathrm{CO} 2$ removals will be assessed and addressed at the project level (Locatelli and Pedroni 2006). Given the long term nature of sinks, and the complex conditions in most rural areas where low-income communities reside, projects that do not involve the local stakeholders stand to fail (Boyd et al. 2007). Carbon project that do not make a concerted effort to integrate their systems into broader community development plans will run the risk of creating new problems (Nelson and de Jong 2003). A/R CDM project has to be carefully designed, otherwise, CDM would result in either leakage or negative welfare implications of the poor (Gundimeda 2004). The involvement of local community is essential to ensure the sustainability of the $\mathrm{A} / \mathrm{R} \mathrm{CDM}$ project.

The purpose of this study is to verify that the risks of non-permanence and leakage exist in the $\mathrm{A} / \mathrm{R} \mathrm{CDM}$ project without full participation of local communities. Then we identify what is necessary to involve them as important players of the A/R CDM project by focusing on their capability. We investigate a registered small-scale $\mathrm{A} / \mathrm{R}$ CDM project in Vietnam which was developed following the current $\mathrm{A} / \mathrm{R} \mathrm{CDM}$ modalities. Previous studies indicated that the rule of the $\mathrm{A} / \mathrm{R} \mathrm{CDM}$ is too complex for the local community and assumed that simple rules were necessary to apply the A/R CDM to community forestry projects (Shin et al. 2007; Minang et al. 2008; Singh 2008; Zorner et al. 2008; Mattsson et al. 2009; Blujdea et al. 2010). But we believe that simplification alone will not assure project sustainability although it is necessary (Boyd et al. 2007). Because the communities succeeded in the community-based management followed historic process of social learning (Klooster and Masera 2000). The community should be capable to manage the forest under the $\mathrm{A} / \mathrm{R}$ CDM scheme. We focus on the capability of the local community to analyze the result conceptually based on the capability approach advocated by Sen (1992).

\section{Method}

\subsection{Small scale A/R CDM project in Vietnam}

The Cao Phong Reforestation Project is a small-scale A/R CDM project that was registered in April 2009 with the UNFCCC. The project site is located in the Cao Phong district, Hoa Binh province, Vietnam, about $100 \mathrm{~km}(\mathrm{~km})$ west of the capital city, Hanoi (Fig. 2). Project development was supported by the Japan International Cooperation Agency (JICA) both financially and technically. Under the project it was planned to establish a tree plantation 


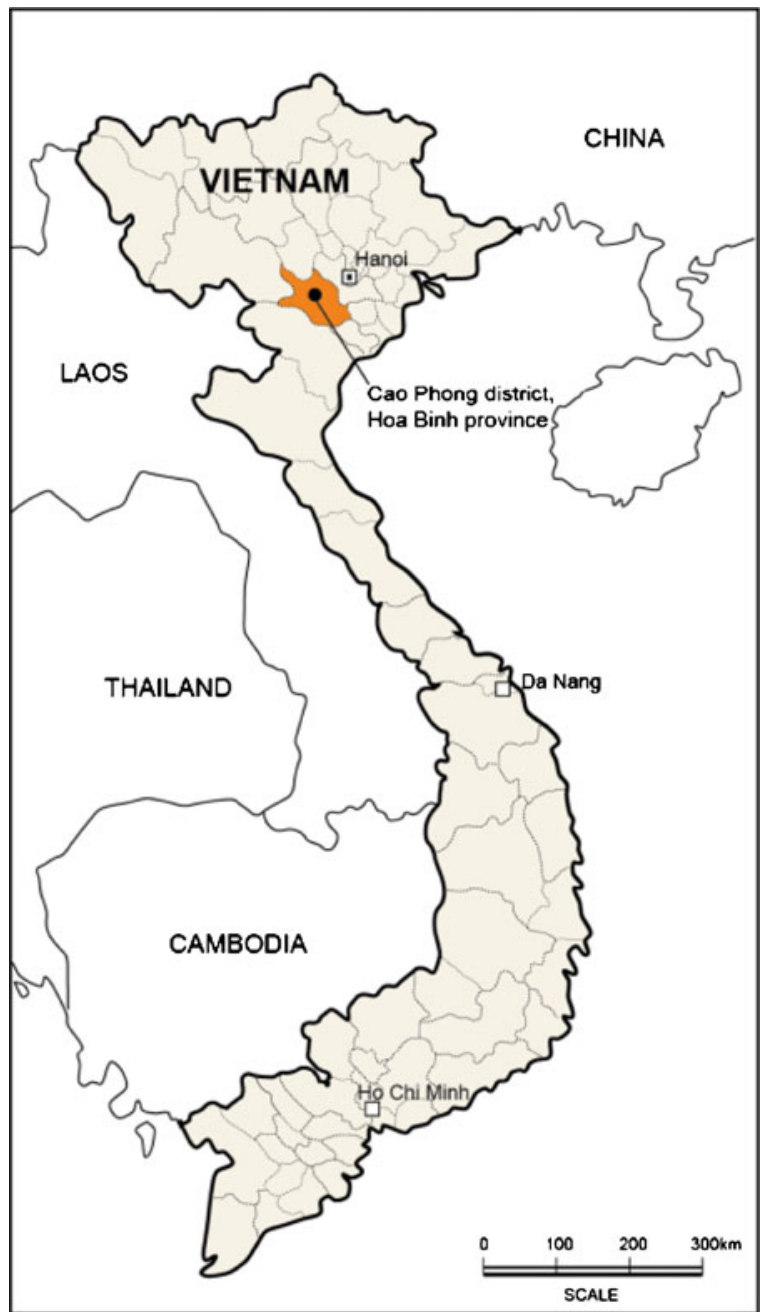

Fig. 2 Location of the study village. Note: The study village named Nhoi-2 village is in Xuan Phong Commune, Cao Phong district, Hoa Binh province, Vietnam

totaling 365 ha (ha) of Acacia mangium and A. auriculiformis on degraded grassland with a 15 -year rotation. The total $\mathrm{CO}_{2}$ removal of this $\mathrm{A} / \mathrm{R} \mathrm{CDM}$ project was estimated at 2,564 $\mathrm{tCO}_{2}$ annually, or $41,029 \mathrm{tCO}_{2}$ over the 16 years of the crediting period (CDM Executive Boad 2009). A non-profit organization (NPO) was established for project administration, and 329 low-income households who held land-use rights in four separate project sites were contracted by the NPO to conduct forest management activities, such as land preparation, planting, thinning, and harvesting. The training of forest management techniques is to be provided to project participants by the NPO (JICA 2008). The benefits from tree harvesting and carbon credits are to be shared between participants and the NPO administering the project. 


\subsection{Study village}

The village of Nhoi-2 in the Xuan Phong commune, Cao Phong district, Hoa Binh province, Vietnam, one of the four sites of the Cao Phong Reforestation Project, was selected as a study site for this investigation. The geographical coordinates of the community center of Nhoi 2 village was $20^{\circ} 42^{\prime} 34^{\prime \prime} \mathrm{N}$ and $105^{\circ} 22^{\prime} 44^{\prime \prime}$ E. There are 78 households of Muong ethnicity in the village, of which 37 joined the project. An area of 23.6 ha around the village was planted with A. mangium in November 2009. Participants received instructions and training on land preparation and tree planting, and the NPO covered the expenses for their labor.

\subsection{Study approach}

The idea of the capability approach (Sen 1992) was conceptually applied in this study. It is widely accepted and not restricted to poverty analysis or development studies, and it can also serve as a framework for project evaluation (Robeyns 2000). The approach consists of "capabilities" and "functionings." A person's capability is the combination of functionings that a person can achieve (Sen 1992). To evaluate a person's capability, important functionings which comprise the capability need to be identified and evaluated. In a smallscale A/R CDM project, local communities should have the capability of managing a planted forest sustainably so that the carbon will be stored long term in the forest. The absence of this capability could lead to project failure, resulting in non-permanence of the carbon sequestration. An effective survey method to identify the capability would be the discussion together with a group of local people because the outsiders alone would not be able to understand the village circumstances and find out root causes of the problems that the villager faces during the implementation of the A/R CDCM. The important functionings for sustainably managing the plantation could be identified through analyzing the process of the discussions.

\subsection{Survey method}

Field surveys were conducted three times in 2010 in Nhoi-2 village. Workshops for group discussion were mainly used to collect the data for this study, along with a questionnaire survey. Individual households were interviewed for more detailed supplementary information that was difficult to obtain at the workshops. The information collected using different methods was then cross-checked and validated.

Basic information was collected in the village in the preliminary survey by using Participatory Rural Appraisal (PRA) tools (Kumar 2003) two months after the initial treeplanting was conducted under the A/R CDM project. We requested members of a village administrative committee to categorize the villagers into high, middle, and low income groups, and then randomly selected four people from the high income and six from the low income households (five males and five females) to participate in a workshop. They were asked to draw a land-use map of the village (Fig. 3), and create an agricultural calendar and an organizational diagram depicting the decision-making system in the village. Then agriculture, land use, and livelihood problems in the village were discussed, and participants were asked about their perceptions of the AR CDM project.

The second workshop was held separately, by gender, to identify and analyze problems with the long-term management of the A/R CDM project, with 10 males and eight females from village households participating. At the same time, a questionnaire survey was 
conducted to identify the impact of the $\mathrm{A} / \mathrm{R} \mathrm{CDM}$ project on the community. In total, interviews were conducted with 68 households out of 78, of which there were $32 \mathrm{~A} / \mathrm{R} \mathrm{CDM}$ project participant households out of $37(86.5 \%)$ and 36 project non-participant households out of $41(87.8 \%)$.

Lastly, people from households whose land use had been affected by the A/R CDM project were selected as attendees based on their responses to the questionnaire survey. Workshops were organized separately by gender for project participants (12 males and 10 females) and project non-participants (eight males and 10 females) to analyze the problems caused by the $\mathrm{A} / \mathrm{R} \mathrm{CDM}$ project and come up with solutions.

\section{Results}

\subsection{Village land use and the A/R CDM project development process}

The land use in the village was illustrated (Fig. 3) and the process of $\mathrm{A} / \mathrm{R}$ CDM project development was clarified at a workshop during the preliminary survey. While paddy rice was the main crop cultivated on most of the flat land, sugarcane had been recently introduced to the village and some households had converted a part of their paddy fields to grow it. They had long been engaged in traditional land-use practices, with each household cultivating its own crops on its allocated land without the need to discuss a holistic land-use plan for the village. Some group activities were identified in the village such as organizations of farmers, women and youth, but these groups were parts of the political system and not voluntarily organized and they mainly came together to share information on things already decided by the village leaders, rather than for discussing and building consensus among all villagers.

The A/R CDM project was implemented in a grassland area covered with some small shrubs on a slope that the villagers called "bare land." The land-use rights here had been officially

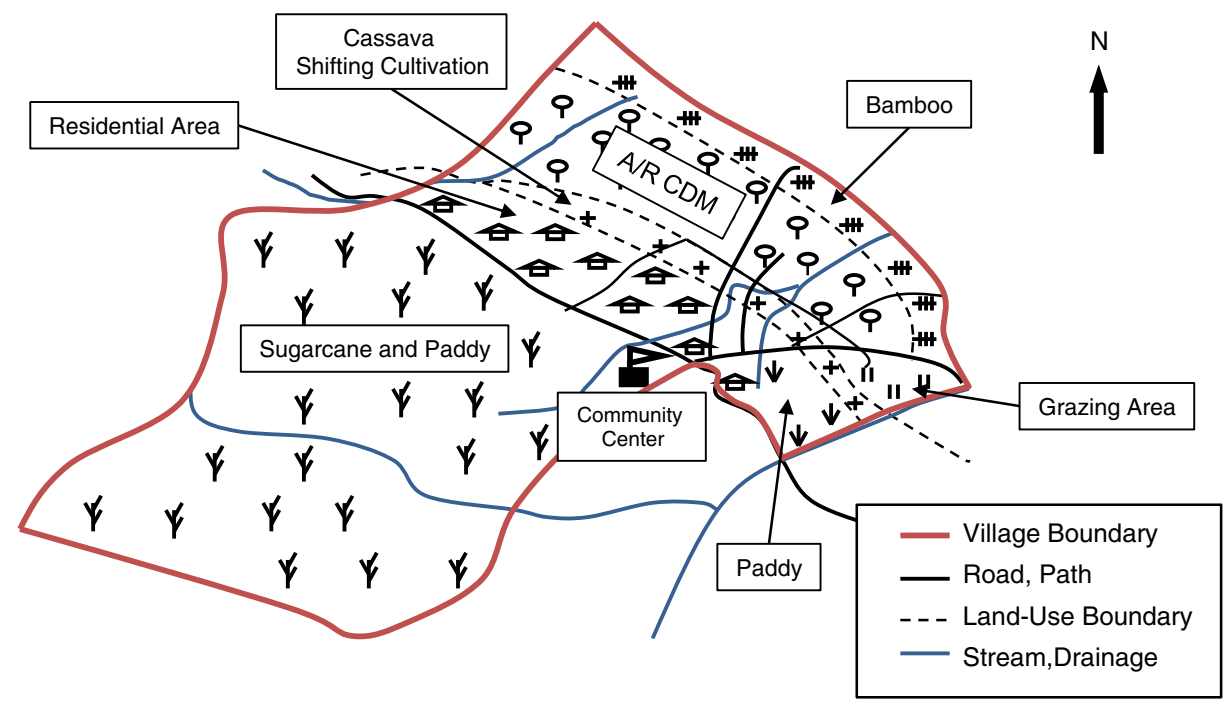

Fig. 3 Land-use of the study village. Note: The map was traced by the author on a land-use map of Nhoi-2 village drawn by villagers at the Participatory Rural Appraisal (PRA) workshop 
allocated to some villagers as forest land, but it customarily remained free to access and any villager could conduct livestock grazing, shifting cultivation, and fuel wood collection here. In the process of the $\mathrm{A} / \mathrm{R} \mathrm{CDM}$ project development in this village, the project developer from the JICA project team first delineated the project area in the bare land following determination of land eligibility conditions under the modalities of the A/R CDM (UNFCCC 2005), then organized meetings to explain the project plan and benefit-sharing to the owners of land-use rights in the area, and obtained their consent. A questionnaire survey was also conducted by the project developer to assess socio-economic conditions and reflect the owners' expectations and preferences regarding tree species in the project design (JICA 2008). Finally, 37 out of 78 households that owned land-use rights agreed to join the project. The A/ $\mathrm{R}$ CDM project plan was announced to all the villagers at a village meeting, and regulations were agreed on, to restrict grazing and shifting cultivation in the project area.

\subsection{Risk of non-permanence}

The problems the project participants (PPs) could envisage with long-term forest management in the A/R CDM project were discussed at a workshop, and five obstacles were identified: (1) unexpected weather events such as cold, drought, or strong winds; (2) destruction of the plantation by grazing and illegal cutting conducted by project nonparticipants (non-PPs); (3) potential decisions by PPs to revert land back to previous land uses, such as grazing and shifting cultivation; (4) forest fires, and (5) insufficient forest management (Table 1). These obstacles could be regarded as direct risk factors that could lead to non-permanence of the A/R CDM project.

\subsection{Risk of leakage: displacement of activities caused by the $\mathrm{A} / \mathrm{R} \mathrm{CDM}$ project}

Figure 4 shows the number of households conducting cattle and buffalo grazing, fuel wood collection, and shifting cultivation to grow cassava before and after the project, respectively, by location, both inside and outside the project area. The location of these three activities significantly changed afterwards (Pearson's chi-square test, $p<0.001$ ), with the number of households conducting them in the project area decreasing remarkably. Both PPs and non-PPs saw the activities they had previously conducted in the project area displaced as land use was restricted for the tree plantation. Grazing and fuel wood collection activities were moved to outside the project area, even to the neighboring village's area over the hill. Most households moved their fuel wood collection to outside the village area, as shrubs were removed during land preparation for the project, and this resulted in $68 \%$ of total households depending on the forest in the neighboring village area as their fuel wood source. This was assumed to cause new GHG emissions outside the project area (thus the leakage) if the displaced households converted to using surrounding forests in substitution for their activities terminated by the project.

Simultaneous to this displacement, some households completely stopped raising cattle and conducting shifting cultivation in the project area (Fig. 4). The total number of cattle in the village largely decreased after the project start from 147 to 78 . Half of the households that had used the project area previously gave up cultivating completely, but the rest still continued planting cassava between tree rows, although they knew that they would have to stop in 1 or 2 years, as the sunlight would eventually not be sufficient for growing cassava under the trees. So displacement will likely occur again in the future and cause leakage some years later. The termination of activities is also closely related to the risk of nonpermanence, because it could become a disincentive for both PPs and non-PPs to 
Table 1 Risk of non-permanence (obstacles) in the A/R CDM project and the solutions identified by project participants

\begin{tabular}{|c|c|}
\hline Risk of non-permanence (obstacles) & Solution \\
\hline Unexpected weather events & None \\
\hline $\begin{array}{l}\text { Destruction of plantation by non } \\
\text { project participants }\end{array}$ & $\begin{array}{l}\text { Form a group of project participants to } \\
\text { collectively protect the plantation } \\
\text { - Raise awareness for forest protection } \\
\text { - Make strict rules and fines for any destruction } \\
\text { - Fence the project area } \\
\text { Ask village leaders to organize the group }\end{array}$ \\
\hline $\begin{array}{l}\text { Land conversion of the plantation } \\
\text { to previous land use decided by } \\
\text { project participants }\end{array}$ & Project authority should manage and control the project \\
\hline Forest fires & $\begin{array}{l}\text { All villagers should participate in fire } \\
\text { prevention and control } \\
\text { - Make fire breaks } \\
\text { - Organize a patrolling team } \\
\text { Ask village leader to make village rules for fire protection }\end{array}$ \\
\hline Insufficient forest management & $\begin{array}{l}\text { Project authority should provide a training } \\
\text { course and adequate direction }\end{array}$ \\
\hline
\end{tabular}

sustainably manage and protect the plantation that itself limited the scope of their daily activities, especially when there was not enough available village land to accommodate any displaced activities.

\subsection{Causes of the risks}

To clarify the causes and effects of the displacement and termination of activities in the project area, a workshop was held separately with PPs and non-PPs to analyze the problems caused by the project. Workshop participants were selected from among the households who said in the questionnaire survey that their activities had been displaced and/or terminated by the project. The result showed that PPs and non-PPs alike had experienced almost the same problems after the project was implemented (Table 2). They had to spend additional time and labor to go further for grazing and fuel wood collection after the project began, and they anticipated a reduction of income from raising livestock, caused by a shortage of feed, because they used to depend heavily on the project area for cattle grazing and cassava production for pigs. Moreover, the access of non-PPs to the project area was limited after the project started because they did not have land-use rights. Some non-PP workshop participants had already experienced a shortage in supply of pig feed and dealt with the problem individually: one converted a part of the cultivating area from other crops to cassava, and another had to buy harvested cassava from other villagers. But they regarded the burden as inevitable, because they thought they could not use the project area without holding the land-use rights, and did not think they could claim their customary rights. Our results indicate that the risk of non-permanence and leakage originated in the shortage of land, because the A/R CDM project implementation restricted land use. Raising livestock was a main income source of the villagers, so they had to find other ways to feed their animals. They consequently had to move their activities outside the project area and would possibly reconvert the plantation area to the previous land use if they could not cover 
(a) Grazing

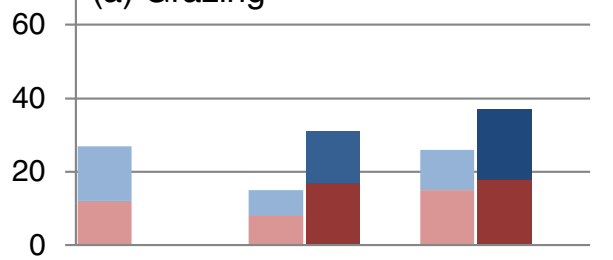

(b) Fuel wood collection

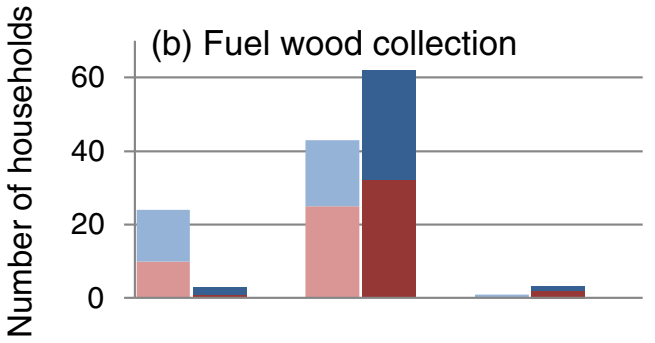

(c) Shifting cultivation

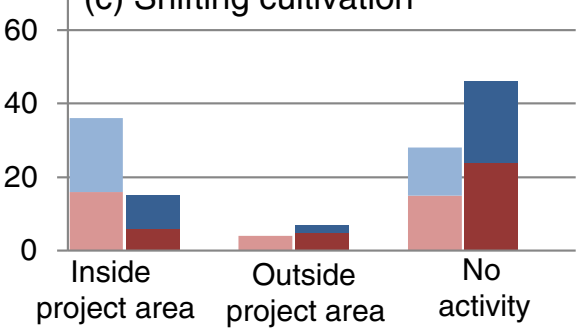

Fig. 4 Location of grazing, fuel wood collection, and shifting cultivation activities before and after A/R CDM project implementation. Note: The difference in distribution between before and after the project was significant in each activity (Pearson's chi-square test, $p<0.001$ ). PP and non-PP refers to project participant and project non-participant of the $\mathrm{A} / \mathrm{R} \mathrm{CDM}$ project, respectively

the feed demands. Therefore, land-use planning at the community level is essential in any $\mathrm{A} / \mathrm{R} \mathrm{CDM}$ project to avoid disruptions caused by a shortage of land.

\subsection{Costs and benefits of the A/R CDM project for the villagers}

Although both PPs and non-PPs shouldered the costs of A/R CDM project implementation, as mentioned above, only PPs believed that the costs they were paying for the project would be compensated by its economic benefits (Table 2). The results from the questionnaire survey showed a significant difference in perception between PPs and nonPPs regarding the benefits from the project (Fig. 5). Only PPs expected an economic benefit from the project (Kolmogorov-Smirnov's Z-test, $p<0.001$ ), and they had already received technical knowledge about tree plantation and economic support for tree-planting activities (Kolmogorov-Smirnov's Z-test, $p<0.001$ ). At the same time, both PPs and non-PPs expected benefits from the ecological services of the forest in the future, such as a moderation of the local climate and improvement in water availability (KolmogorovSmirnov's Z-test, $p>0.05$ ). It was assumed that non-PPs would have very little incentive to protect the plantation and that the lack of incentive might cause them to resume grazing and 
Table 2 Status of grazing, fuel wood collection, and shifting cultivation activities before and after A/R $\mathrm{CDM}$ project implementation, the problems caused by the project, and the solutions identified by villagers selected to attend the workshop

\begin{tabular}{|c|c|c|c|c|}
\hline & & Grazing & Fuel wood collection & Shifting cultivation \\
\hline Before project & $\begin{array}{l}\mathrm{PP} \\
\text { non-PP }\end{array}$ & \multicolumn{3}{|c|}{ - Anyone could conduct the activities } \\
\hline \multirow[t]{3}{*}{$\begin{array}{l}\text { After project } \\
\text { (present) }\end{array}$} & \multirow[t]{2}{*}{$\mathrm{PP}$} & - Going further & \multirow[t]{3}{*}{$\begin{array}{l}\text { - Going greater } \\
\text { distance }\end{array}$} & $\begin{array}{l}\text { - Continuing cultivation } \\
\text { between the tree rows } \\
\text { for } 1 \text { to } 2 \text { years }\end{array}$ \\
\hline & & $\begin{array}{l}\text { - Keeping cattle } \\
\text { in stall }\end{array}$ & & $\begin{array}{l}\text { - Stopped cultivating } \\
\text { as no land use right }\end{array}$ \\
\hline & non-PP & $\begin{array}{l}\text { - Gave up and } \\
\text { sold cattle }\end{array}$ & & $\begin{array}{l}\text { - Cultivating alternate area } \\
\text { - Buying cassava } \\
\text { from others }\end{array}$ \\
\hline \multirow[t]{4}{*}{ Problems } & \multirow[t]{3}{*}{ PP } & \multicolumn{3}{|c|}{ - Problems maybe compensated by the profit from the project } \\
\hline & & $\begin{array}{l}\text { - Time and labor } \\
\text { consuming }\end{array}$ & $\begin{array}{l}\text { - Time and labor } \\
\text { consuming }\end{array}$ & $\begin{array}{l}\text { - Difficult to find } \\
\text { alternate land }\end{array}$ \\
\hline & & $\begin{array}{l}\text { - Lack of grass for } \\
\text { feeding cattle }\end{array}$ & $\begin{array}{l}\text { - Serious problem will } \\
\text { be caused if use of } \\
\text { the forest in the next } \\
\text { village is prohibited }\end{array}$ & - Lack of cassava for pigs \\
\hline & non-PP & $\begin{array}{l}\text { - Income reduced } \\
\text { by giving up } \\
\text { cattle raising }\end{array}$ & & $\begin{array}{l}\text { - Income will be reduced } \\
\text { if giving up pig raising }\end{array}$ \\
\hline \multirow[t]{2}{*}{ Solutions } & PP & \multicolumn{3}{|c|}{ - Use of the project area is not allowed anymore } \\
\hline & non-PP & $\begin{array}{l}\text { - To learn fodder } \\
\text { production technique } \\
\text { but the land is limited }\end{array}$ & - Not necessary & $\begin{array}{l}\text { - To arrange the land use } \\
\text { to produce pig food but } \\
\text { the land is limited }\end{array}$ \\
\hline
\end{tabular}

PP and non-PP refers to project participant and project non-participant of the A/R CDM project, respectively

illegal logging in the project area, which PPs pointed out led to risks of non-permanence (Table 1).

\section{Analysis and discussion}

\subsection{Participation of all stakeholders}

It has been found that the participation of all relevant stakeholders in the decision-making process is important in any community forestry project (Adhikari et al. 2007; Shin et al. 2007). The design of the Cao Phong Reforestation Project was led by the project developer and the formal owners of land-use rights, who were considered stakeholders in the project, only joined the project as PPs. Our results suggest that even those who did not hold land rights were also important stakeholders and had an influence on the success of forest management in the project. The plantation project accompanied large land-use changes in the community (Fig. 4), and a number of people in the village used the area for their livelihoods before project implementation, even though the project area was considered to be bare land. In this project, non-PPs and PPs both had to shoulder the cost of project implementation through the displacement and termination of their activities (Fig. 4 and 


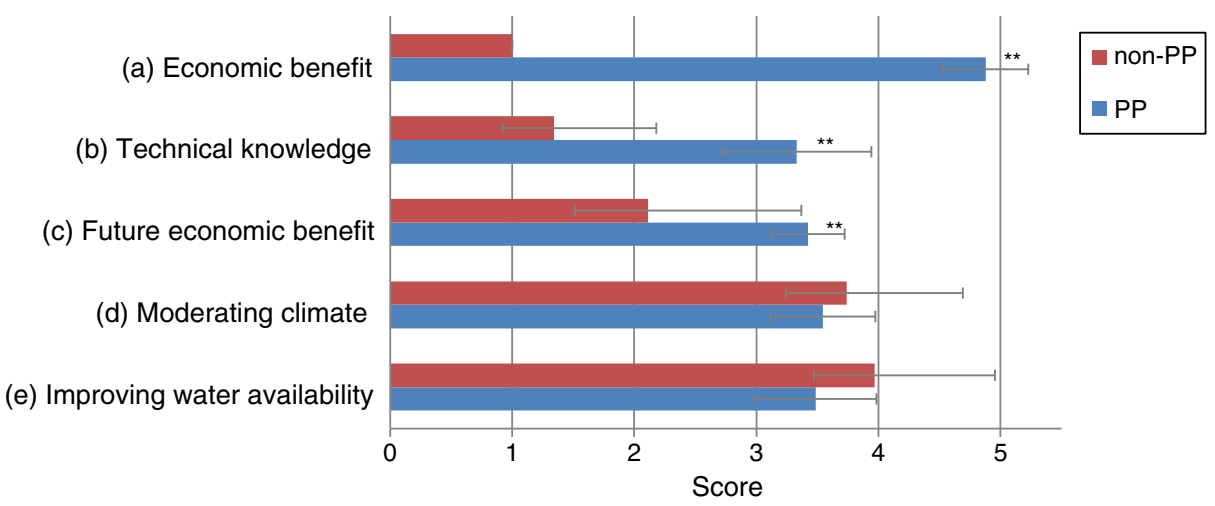

Fig. 5 Different perceptions of benefits from the A/R CDM project. Note: Interviewees were asked to score on an ascending scale of 1 to 5 their answers to the following questions: a Did you get an economic benefit from the project? b Did you get technical knowledge from the project? c Do you think you will get any economic benefit from the plantation in the future? d Do you think the plantation will moderate the local climate? e Do you think the plantation will improve water availability? Significance was tested using Kolmogorov-Smirnov's Z-test $(* * p<0.001)$. PP and non-PP refers to project participant and project nonparticipant of the A/R CDM project, respectively

Table 2), but they would not receive any compensation or incentives from the project. NonPPs wouldn't have the motivation to collectively participate in managing the forest, and yet PPs considered them to be destroyers of the forest (Table 1). PPs realized at the workshop that the cooperation of all village members was necessary for forest fire prevention and control (Table 1), with a number of interviewees saying that "all villagers should plant together and protect together to ensure the success of the project." Our study indicated that exclusion of non-landowners from the project would increase the risk of non-permanence and leakage, and possibly generate disparity between two groups in the community.

Our results suggest that it is necessary to review the carbon rights scheme. Wood harvested in a large timber production project generally belongs to the land owner. In a forest carbon project, as well, it is fundamentally important to assure property and land-use rights (Muradian et al. 2010). In the Cao Phong Reforestation Project, carbon rights were allocated only to the land-use right holders. Moreover, land-use rights and actual land use did not strictly coincide - a common situation in rural mountainous areas in Vietnam, as observed in some studies (Sikor 2001; Castella et al. 2006). This situation made it difficult for the community to agree on the sharing of carbon benefits, including non-land owners who are important stakeholders in forest management activities. On the other hand, our results suggest that the benefits from ecological services of the forest were shared among all villagers (Fig. 5). The carbon sequestration that occurs from the project should also be considered to be a common ecological service for the village. These benefits represent a new aspect of negotiation among project stakeholders, beyond existing land tenure, and an opportunity for participation in the project by all members in the village. In short, the carbon rights should be allocated to all stakeholders in an A/R CDM project.

\subsection{Capability: readiness for an A/R CDM project}

Conventionally, forest management and farming skills are seen as important functionings in the capability of conducting sustainable forest management in community. The necessity of these skills to sustainably manage a planted forest was also identified by the villagers in this 
study (Table 1, Table 2). Our results also suggest that the important functionings are not limited to those skills. The community's capability for land-use planning was closely related to its capability to manage the forest sustainably and to prevent a shortage of land, which was the main factor causing project non-permanence and leakage risk. Consensus building and collective action would be considered the necessary functionings the villagers should obtain for this capability. Formation of community consensus through active discussion, with all participating, is of utmost importance in the process of land-use planning, as shown in the previous section, and it would be necessary for establishing community engagement in any $\mathrm{A} / \mathrm{R} \mathrm{CDM}$ project. Collective action would be directly applicable to conducting forest management activities in the project, such as patrolling of the project area for protection. Those two functionings are also essential for the villagers to participate in the decision-making process which was mentioned in the previous section and to have strong sense of ownership on the project which motivate them for sustaining the project.

However, the villagers had no experience in making a community land-use plan (Section 4.1) and had a strong tendency to depend on the village leader and project authority for making decisions (Table 1). Non-PPs didn't think of claiming their customary land-use rights. They shouldered the inconveniences brought about by the project, and simply followed the rules announced at the village meetings (Table 2). Their capability for land-use planning and sustainable forest management was evaluated as weak. It was assumed that this was because they had long been under a top-down system, far removed from any participatory decision-making process. Similar problems were reported in a registered $\mathrm{A} / \mathrm{R} \mathrm{CDM}$ project in China, with some communities dropping out from project implementation because they could not solve land-use conflicts, and it was concluded that social capital in the communities was lacking (Gong et al. 2010). The lack of capability of villagers to participate in community forest carbon projects and sustain their activities has been mentioned in earlier studies, although the analytical approaches were different from ours (Gundimeda 2004; Shin et al. 2007; Jindal et al. 2008; Minang et al. 2008; Oestreicher et al. 2009; Clements et al. 2010; Gong et al. 2010).

The A/R CDM was originally aimed at creating an economic incentive for local communities to select the forest land-use option from among other competing land-use options. However the local communities would not be able to make good use of this opportunity if their level of capability was low. It is important to strengthen non-monetary individual and collective motivations such as the need for capacity, beyond the idea incentive in payment for ecosystem services (Kosoy et al. 2008). Capability development for local people should be included at an early stage as readiness phase in the $\mathrm{A} / \mathrm{R}$ CDM project.

\subsection{Additional project cost and funding source of capability development}

It was assumed that the $\mathrm{A} / \mathrm{R}$ activity was a low-cost mitigation measure (IPCC 2007), but the cost for tree plantation of 365 ha in the Cao Phong A/R CDM project was approximately $\$ 546,000$, with an estimated removal of $41,029 \mathrm{tCO}_{2}$ (JICA 2008) and the CDM-related cost was estimated to be $\$ 236,100$ (Seeberg-Elverfeldt 2010 ), or $30 \%$ of the total cost of the A/R CDM project implementation. The total project implementation cost of Cao Phong A/R CDM project was estimated to be $\$ 19.1 / \mathrm{tCO}_{2}$. The transaction cost for $\mathrm{CDM}$ was a major negative factor, especially in a small-scale community forestry project (Skutsch 2005).

In addition, the value of the project area seemed to be underestimated in Cao Phong project. The outsider like project developers saw the "bare land" project area valueless, but 
in fact the villagers were great users of the area (McElwee 2009). To compensate this opportunity cost in the $\mathrm{A} / \mathrm{R} \mathrm{CDM}$ project, some additional cost on top of the existing $\mathrm{A} / \mathrm{R}$ CDM project costs would be required. Our study showed the possibility to partially reduce the cost for compensating the opportunity cost by the capability development of the local community for the skills alternating the activities conducted in the project area before starting the project (e.g. skill for fodder production, new source of energy alternating fuel wood). Further analysis is necessary to discuss the economic efficiency between monetary compensation and capability development in the project. We roughly estimated the cost for capability development, including fodder production and biogas technology transfer and workshops for land-use planning, at \$298,100 (Teune 2007; JICA 2008), which finally increased the emission reduction cost to $\$ 26.3 / \mathrm{tCO}_{2}$. It is difficult to expect this additional cost to be borne by carbon investors under the current A/R CDM system (Harvey et al. 2010), where project financing depends completely on market mechanisms and the carbon credit from $\mathrm{A} / \mathrm{R}$ CDM projects is tended to be low in the market (Tal and Gordon 2010). It is highlighting the need for a new funding source for development of $\mathrm{A} / \mathrm{R} \mathrm{CDM}$ readiness before project implementation.

The importance of capability development under the CDM has already been acknowledged by the UNFCCC, with the Nairobi Framework created to help developing countries improve their level of participation in the CDM through capacity building (UNFCCC 2007). But capacity building under this framework mainly focused on promoting understanding and institutional improvements at the national level. REDD +adopted a phased approach and provides a phase for readiness for capacity building prior to the market-based implementation phase (Streck et al. 2009a). The funds for the readiness phase are typically secured from bilateral and multilateral sources. In the $A / R$ $\mathrm{CDM}$ as well, the readiness phase should be introduced institutionally along with funds for capability development. One possible funding source for A/R CDM readiness would be from international, bilateral, and multilateral funding like REDD+. It is reasonable to use public funding in addition to market-based private funds for capability development, as it would result in sustainable development in the host country. However, utilization of official development assistance (ODA) for the CDM was regarded a diversion and was restricted in the current CDM institutional arrangements (UNFCCC 2001). ODA involvement in $\mathrm{CDM}$ projects may increase the chance of attracting private-sector investment in neglected regions and specific project types, especially community-based projects (Dutschke and Michaelowa 2006). Another option for the readiness-funding source may be the Adaptation Fund, which is financed mainly from a share of proceeds from CDM projects, amounting to $2 \%$ of carbon credits (certified emission reductions, or CERs) issued for a CDM project, and could fund concrete adaptation projects in developing countries through the Global Environmental Facility (UNFCCC 2011a). The share of proceeds amounted to \$130 million from May 2009 to October 2010 (Adaptation Fund 2009). It would be quite plausible to redistribute the proceeds of a CDM project for its further development.

\section{Conclusions}

REDD + may become a more important forestry mitigation measure in the post KP period, but the A/R CDM will still be important as provides opportunities for countries where their forest area has already been stabilized or mostly cleared (Fig. 1). Reforming the A/R CDM would be one of key issues to be discussed to establishing equitable global mechanism for 
the climate mitigation which allows all developing countries to participate, though its importance was not clearly recognized actually.

Although our discussion was based on only one case study in the A/R CDM project in Vietnam and further economic studies of this project is required for more complete analysis, our findings may advance understanding of the point that we should give considerable attention to promote $\mathrm{A} / \mathrm{R} \mathrm{CDM}$ by offering some insights into the operation of local community forestry activities. Careful attention to local realities and needs, within project planning, design, implementation, monitoring and ex-post evaluation, can go a long way in ensuring the sustainable life of projects and the credibility of the Protocol as a tool for promoting real sustainable development (Boyd et al. 2007).

Our study suggested that participation of all stakeholders in the community to the $A / R$ $\mathrm{CDM}$ project beyond existing land tenure and adequate carbon benefit sharing according to the level of contribution to the project would reduce the risk of non-permanence. To ensure the participation, the community should have capability such as consensus building and collective action. The risk of leakage would be minimized if the community has alternative measures to the conventional activities before starting the project activities. The sustainability of the project would be secured by capability development of the local community and its funding mechanism should be prepared in the A/R CDM.

Acknowledgements The authors express their gratitude to all the villagers of Nhoi-2 who participated in the interviews and workshops for their cooperation and friendly demeanor. They also thank Ms. Do Thi Ngoc Bich, Mr. Hoang Ngoc Y, Ms. Nguyen Thi Phuong, and many other researchers at Vietnam Forestry University for assisting with the field survey, as well as Mr. Akihiko Sasaki and Mr. Tomoki Nakamura (Nippon Koei Co. Ltd.) for supplemental information on the Cao Phong project, and Dr. Henry Scheyvens (Institute for Global Environmental Strategies) for his valuable comments on an earlier draft of this paper. The valuable comments of anonymous referees are also acknowledged. This study was funded by the Environment Research and Technology Development Fund (E-031) of the Japan Ministry of Environment and Grants-in-Aid for Scientific Research (B22405025).

Open Access This article is distributed under the terms of the Creative Commons Attribution Noncommercial License which permits any noncommercial use, distribution, and reproduction in any medium, provided the original author(s) and source are credited.

\section{References}

Adhikari B, Williams F, Lovett JC (2007) Local benefits from community forests in the middle hills of Nepal. Forest Policy Econ 9(5):464-478

Adaptation Fund (2009) Financial status of the adaptation fund trust fund and the administrative trust fund (as at 30 September 2009)

Blujdea V, Bird DN, Robledo C (2010) Consistency and comparability of estimation and accounting of removal by sinks in afforestation/reforestation activities. Mitg Adapt Strateg Glob Change 15(1):1-18

Boyd E, Gutierrez M, Chang MY (2007) Small-scale forest carbon projects: adapting CDM to low-income communities. Global Environ Chang 17(2):250-259

Castella JC, Boissau S, Thanh NH et al (2006) Impact of forestland allocation on land use in a mountainous province of Vietnam. Land Use Policy 23(2):147-160

CDM Executive Boad (2009) Project design document for Cao Phong reforestation project Project No 2363

Clements T, John A, Nielsen K et al (2010) Payments for biodiversity conservation in the context of weak institutions: comparison of three programs from Cambodia. Ecol Econ 69(6):1283-1291

Dargusch P, Harrison S, Thomas S (2010) Opportunities for small-scale forestry in carbon markets. SmallScale Forest 9(4):397-408

Dutschke M, Michaelowa A (2006) Development assistance and the CDM - How to interpret 'financial additionality'. Environ Dev Econ 11:235-246

FAO (2010) Global forest resource assessment 2010 main report. FAO, Rome 
Gong YZ, Bull G, Baylis K (2010) Participation in the world's first Clean Development Mechanism forest project: the role of property rights, social capital and contractual rules. Ecol Econ 69(6):1292-1302

Gundimeda H (2004) How 'sustainable' is the 'sustainable development objective' of CDM in developing countries like India? Forest Policy Econ 6(3-4):329-343

Harvey CAZO, Papageorgiou S, Parra A (2010) What is needed to make REDD+work on the ground? Lessons learned from pilot forest carbon initiatives. Arlington, Verginia, USA, p 121

IPCC (2007) Climate change 2007: Working group III: mitigation of climate change. Cambridge University Press, Cambridge

JICA (2008) The study on capacyty development for AR-CDM promotion in the Socialist Republic of Vietnam interim report (2). Tokyo

Jindal R, Swallow B, Kerr J (2008) Forestry-based carbon sequestration projects in Africa: potential benefits and challenges. Nat Resour Forum 32:116-130

Klooster D, Masera O (2000) Community forest management in Mexico: carbon mitigation and biodiversity conservation through rural development. Global Environ Change 10:259-272

Kosoy N, Corbera E, Brown K (2008) Participation in payments for ecosystem services: case studies from the Lacandon rainforest, Mexico. Geoforum 39:2073-2083

Kumar S (2003) Methods for community participation: a complete guide for practitioners. ITDG Publishing, UK

Lasco RD, Evangelista RS, Pulhin FB (2010) Potential of community-based forest management to mitigate climate change in the Philippines. Small-Scale Forest 9(4):429-443

Locatelli B, Pedroni L (2006) Will simplified modalities and procedures make more small-scale forestry projects viable under the clean development mechanism? Mitg Adapt Strat Glob Change 11:621-643

Marechal K, Hecq W (2006) Temporary credits: a solution to the potential non-permanence of carbon seuestration in forsts? Ecolog Econ 58:699-716

Mattsson E, Ostwald M, Nissanka SP et al (2009) Recovery and protection of coastal ecosystems after tsunami event and potential for participatory forestry CDM - Examples from Sri Lanka. Ocean Coast Manage 52(1):1-9

McElwee P (2009) Reforesting "bare hills" in Vietnam: social and environmental consequesnces of the 5 Million Hectare Reforestation Program. Ambio 39(6):325-333

Minang PA, McCall MK, Bressers HTA (2007) Community capacity for implementing clean development mechanism projects within community forests in Cameroon. Environ Manage 39:615-630

Minang PA, McCall MK, Skutsch MM et al (2008) A data support infrastructure for Clean Development Mechanism forestry implementation: an inventory perspective from Cameroon. Mitg Adapt Strateg Glob Change 13(2):157-178

Muradian R, Corbera E, Pascual U et al (2010) Reconciling theory and practice: an alternative conceptual framework for understanding payments for environmental services. Ecol Econ 69 (6): $1202-1208$

Nelson KC, de Jong BHJ (2003) Making global initiatives local realities: carbon mitigation projects in Chiapas, Mexico. Global Environ Change 13:19-30

Oestreicher JS, Benessaiah K, Ruiz-Jaen MC et al (2009) Avoiding deforestation in Panamanian protected areas: an analysis of protection effectiveness and implications for reducing emissions from deforestation and forest degradation. Global Environ Change 19(2):279-291

Robeyns I (2000) An unworkable idea or a promising alternative? Sen's capability approach re-examined. Discussion Paper Series. Center for Economic Studies, Katholieke Universiteit Leuven, p 32

Rocha MT (2008) Is there a rople or even a future in the post-2012 regime? In: Olsen KH, Fenhann J (eds) A Reformed CDM. UNEP Riso Centre, Denmark, p 183

Seeberg-Elverfeldt C (2010) Carbon finance possibilities for agriculture, forestry and other land use projects in a smallholder context. Environment and natural resource management working paper. FAO, Rome, p 30

Sen A (1992) Inequity reexamined. Harvard University Press, Cambridge

Shin MY, Miah MD, Lee KH (2007) Potential contribution of the forestry sector in Bangladesh to carbon sequestration. J Environ Manage 82(2):260-276

Sikor T (2001) The allocation of forestry land in Vietnam: did it cause the expansion of forests in the northwest? Forest Pol Econ 2(1):1-11

Singh PP (2008) Exploring biodiversity and climate change benefits of community-based forest management. Global Environ Chang 18(3):468-478

Skutsch MM (2005) Reducing carbon transaction costs in community-based forest management. Clim Policy $5(4): 433-443$

Streck C, Gomez-Echeverri L, P. G et al (2009a) REDD+institutional options assessment. Washington DC

Streck C, Tuerk A, Schlamadinger B (2009b) Foresty offsets in emissions trading systems: a link between systems? Mitg Adapt Strateg Glob Change 14(5):455-463 
Tal A, Gordon J (2010) Carbon cautious: Israel's afforestation experience and approach to sequestration. Small-Scale Forest 9(4):409-428

Teune B (2007) The biogas programme in Vietnam; Amazing results in poverty reduction and economic development. Boiling Point (53):11-13

UN (1998) Kyoto Protocol to the United Nations Framework Convention on Climate Change

UNFCCC (2001) Report of the Conference of the Parties on its seventh session, held at Marrakesh from 29 October to 10 November 2001. FCCC/CP/2001/13/Add.2

UNFCCC (2005) Simplified modalities and procedures for small-scale afforestation and reforestation project activities under the Clean Development Mechanism in the first commitment period of the Kyoto Protocol and measures to facilitate their implementation, report of the Conference of the Parties serving as the meeting of the parties to the Kyoto Protocol on its first session, held at montreal from 28 November to 10 December 2005. FCCC/KP/CMP/2005/8/Add.1 Decision6/CMP.1

UNFCCC (2007) Report of the Conference of the Parties serving as the meeting of the Parties to the Kyoto Protocol on its second session, held at Nairobi from 6 to 17 November 2006. FCCC/KP/CMP/2006/10/Add.1

UNFCCC (2010) Report of the Conference of the Parties on its sixteenth session, held in Cancun from 29 November to 10 December 2010. FCCC/CP/2010/7/Add.1

UNFCCC (2011a) Adaptation fund. http://unfccc.int/cooperation_and_support/financial_mechanism/ adaptation_fund/items/3659.php. Cited June 142011

UNFCCC (2011b) CDM project search. http://cdm.unfccc.int/Projects/projsearch.html. Cited May 202011

Zorner RJ, Trabucc A, Bossio DA et al (2008) Climate change mitigation: a spatial analysis of global land suitability for Clean Development Mechanism afforestation and reforestation. Agr Ecosyst Environ 126 $(1-2): 67-80$ 